\title{
Power Flow Models of GaN Based Partial Parallel Dual Active Bridge (P2DAB) DC-DC Converter
}

Xiao, Yudi; Zhang, Zhe; Andersen, Michael A. E.

Published in:

Proceedings of 2nd IEEE International Power Electronics and Application Conference and Exposition

Link to article, DOI:

10.1109/PEAC.2018.8590552

Publication date:

2018

Document Version

Peer reviewed version

Link back to DTU Orbit

Citation (APA):

Xiao, Y., Zhang, Z., \& Andersen, M. A. E. (2018). Power Flow Models of GaN Based Partial Parallel Dual Active Bridge (P2DAB) DC-DC Converter. In Proceedings of 2nd IEEE International Power Electronics and Application Conference and Exposition IEEE. https://doi.org/10.1109/PEAC.2018.8590552

\section{General rights}

Copyright and moral rights for the publications made accessible in the public portal are retained by the authors and/or other copyright owners and it is a condition of accessing publications that users recognise and abide by the legal requirements associated with these rights.

- Users may download and print one copy of any publication from the public portal for the purpose of private study or research.

- You may not further distribute the material or use it for any profit-making activity or commercial gain

- You may freely distribute the URL identifying the publication in the public portal 


\section{Power Flow Models of GaN Based Partial Parallel Dual Active Bridge (P2DAB) DC-DC Converter}

Yudi Xiao

Department of Electrical Engineering

Technical University of Denmark

Kgs. Lyngby, Denmark

yudxiao@elektro.dtu.dk

\author{
Zhe Zhang \\ Department of Electrical Engineering \\ Technical University of Denmark \\ Kgs. Lyngby, Denmark \\ zz@elektro.dtu.dk
}

\author{
Michael A. E. Andersen \\ Department of Electrical Engineering \\ Technical University of Denmark \\ Kgs. Lyngby, Denmark \\ ma@elektro.dtu.dk
}

\begin{abstract}
This paper presents a lossless power flow model and an improved power flow model of the Partial Parallel Dual Active Bridge $\left(P^{2} D A B\right)$ dc-dc converter with single-phase-shift modulation (SPSM). The improved model considers the dead time and the parasitic elements. A GaN based $P^{2} D A B$ converter prototype is built to verify the models. The lossless model is more accurate than the other at small phase shift region, while the improved one is more accurate at medium and large phase shift region. The cause of the errors are discussed, and the solution to improve the accuracy is provided. Moreover, the improved model provides more details about the power flow characteristics than the lossless model.
\end{abstract}

Keywords-power flow model, dual active bridge converter, GaN

\section{INTRODUCTION}

Bidirectional converters, which can interface energy storage system (ESS) to power conversion systems, have gained increasing attention [1]-[3]. Due to its small number of components, symmetrical structure, isolation capability and soft switching properties, the dual active bridge (DAB) converter has become a popular topology [4] - [6].

In [7], a Partial Parallel Dual Active Bridge ( $\left.\mathrm{P}^{2} \mathrm{DAB}\right)$ converter, whose topology is shown in Fig. 1, is proposed. The basic idea of the structure is connecting the circuit parts, which need to carry high current, in parallel and connecting the circuit parts, which need to block high voltage, in series. The ac current balancing between the paralleled full-bridges (FBs) are inherently ensured by the winding series connection on the high-voltage (HV) side ( $V_{l}$ side in Fig. 1). The basic control strategy of the $\mathrm{P}^{2} \mathrm{DAB}$ converter is single-phase-shift modulation (SPSM), i.e. add phase shift between the FB on the HV side (HVFB) and the FBs on the LV side (LVFB). In [7], in addition to the phase shift between the HVFB and the LVFBs, a phase shift is added between the LVFBs to increase the efficiency at the low power ranges. Power flow equations of the $\mathrm{P}^{2} \mathrm{DAB}$ converter are derived in [7]. However, these equations are ideal, neither losses nor dead time were considered. In [8], a lossless power flow model with consideration of dead time is derived for the DAB converter with SPSM. The effect of dead time on the power flow is addressed. In [9], a power flow model with consideration of both of the losses and the dead time is derived for the DAB converter with SPSM. And the power plateau and the anti-power phenomenon are discussed. These two phenomenon is addressed to have influences on the power flow control of the DAB converter with SPSM. Since the $\mathrm{P}^{2} \mathrm{DAB}$ converter is a DAB-based converter, it is thereby worthy to derive an improved power flow model for it with consideration of

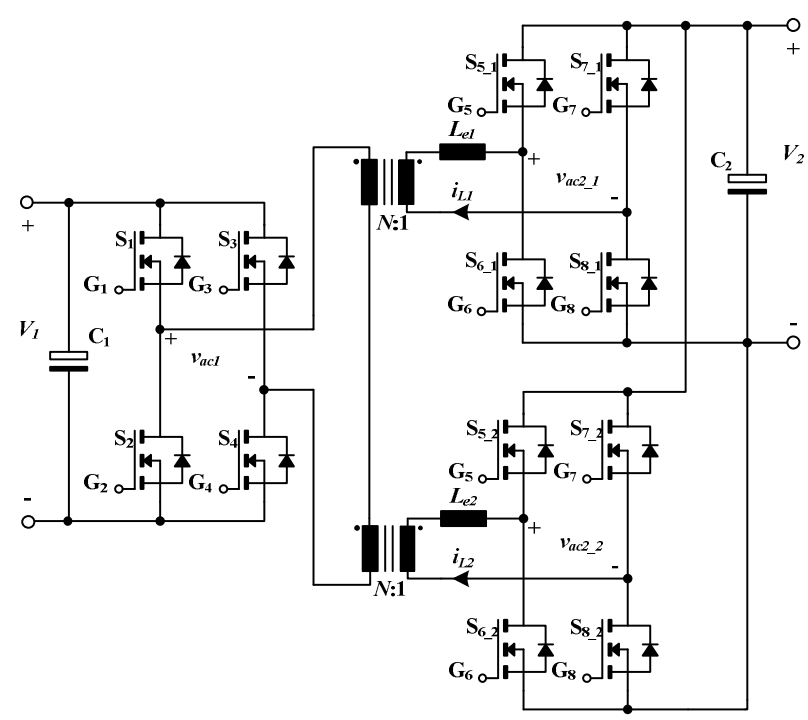

Fig. 1: Topology of the $\mathrm{P}^{2} \mathrm{DAB}$ converter

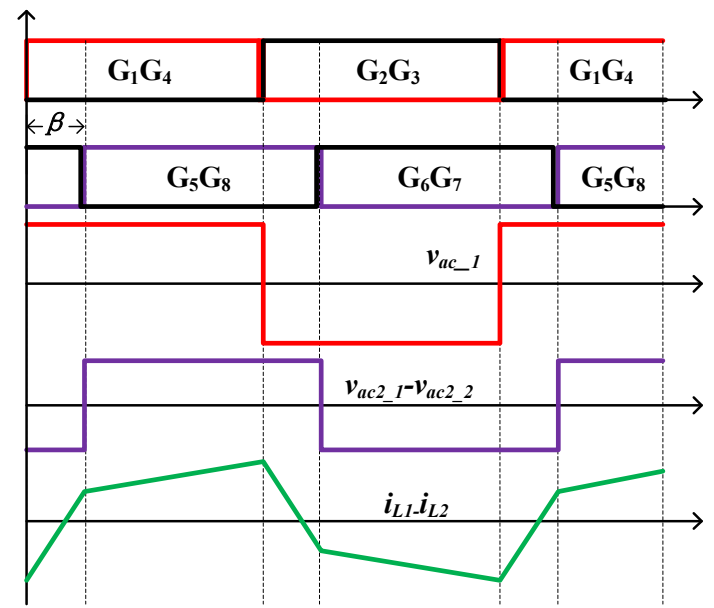

Fig. 2: Typical waveforms of the $\mathrm{P}^{2} \mathrm{DAB}$ converter with SPSM in lossless model, $V_{l} \rightarrow V_{2}, V_{l}>2 V_{2}$

the losses and the dead time. With the improved model, the accurate prediction of the transferred power and the deep investigation of power flow characteristics of the $\mathrm{P}^{2} \mathrm{DAB}$ converter can be expected.

The paper is organized as follows: After this introduction, the modeling of the power flow of the $\mathrm{P}^{2} \mathrm{DAB}$ converter with SPSM is given in Section II. In Section III, both models are compared with the simulations. In Section IV, both models are compared with the experiments on a $\mathrm{P}^{2} \mathrm{DAB}$ converter prototype. Conclusions are made in Section V.

\section{MODELLING OF THE P²DAB CONVERTER}

\section{A. Lossless Power Flow Model of the P PAB Converter}

In the lossless model, the following assumptions are made: 
- The power semiconductor switches are ideal.

- Both transformers are ideal.

- Dead time is zero.

Typical waveforms of the $\mathrm{P}^{2} \mathrm{DAB}$ converter with SPSM under $V_{1} \rightarrow V_{2}$ and $V_{l}>2 N V_{2}$ are shown in Fig. 2. $V_{1} \rightarrow V_{2}$ denotes the operation where power flows from $V_{I}$ to $V_{2}$, and $V_{2} \rightarrow V_{1}$ vice versa. $\beta$ represents the electrical angle by which $\mathrm{G}_{1} \& \mathrm{G}_{4}\left(\mathrm{G}_{2} \& \mathrm{G}_{3}\right)$ leading $\mathrm{G}_{5} \& \mathrm{G}_{8}\left(\mathrm{G}_{6}\right.$ $\left.\& \mathrm{G}_{7}\right)$, and $\beta$ is also the phase difference between $v_{a c 1}$ and $v_{a c 2_{2} 1}\left(\right.$ or $v_{a c 2}$ ) since the dead time is ignored in the lossless model. In [4], the lossless power flow model for the DAB converter with SPSM was derived. Using the same deriving procedures in [4], the lossless power flow model of the $\mathrm{P}^{2} \mathrm{DAB}$ converter with SPSM can be expressed by (1), where $P_{\text {in }}$ is the averaged power sourcing from $V_{l}, P_{o}$ is the averaged power sinking into $V_{2}$, $f_{s}$ is the switching frequency, and $L_{e}$ denotes the inductance of $L_{e 1}$ or $L_{e 2} . d$ is the unified phase shift angle, whose expression is given in (2).

$$
\begin{gathered}
P_{i n}=P_{o}=\frac{\frac{V_{1}}{N} V_{2}(1-|d|) d}{2 f_{s} L_{e}} \\
d=\frac{\beta}{\pi}
\end{gathered}
$$

\section{B. Improved Power Flow Model of the P $P^{2} D A B$ Converter}

Compared to the lossless model, the following circuit elements are considered in the improved model:

- The on-state resistances $\left(R_{o n H}, R_{o n L}\right)$ and the freewheeling voltage drops $\left(V_{d H}, V_{d L}\right)$ of the switches.

- The leakage inductances $\left(L_{t r p}, L_{t r s}\right)$ and the winding resistances $\left(R_{t r p}, R_{t r s}\right)$ of the transformers.

- The winding resistances $\left(R_{e}\right)$ of the external inductors.

- The dead time $T_{d}$.

Fig. 3 shows the derivation of the equivalent circuit of the $\mathrm{P}^{2} \mathrm{DAB}$ converter. In Fig. 3(a), the three FBs are firstly simplified to be three ac voltage sources, which are the voltages across the switching nodes of the three FBs, respectively. In Fig. 3(b), all the circuit elements on the LV side of the transformer are referred to the HV side. In Fig. 3(c), all the circuit elements in series are combined to further simplify the equivalent circuit. $v_{a c 2_{-} l}$ and $v_{a c 2} 2$ are assumed to be the same, thereby both of them are represented by $v_{a c 2}$. The expressions of $L_{a c}$ and $R_{a c}$ are given in (3).
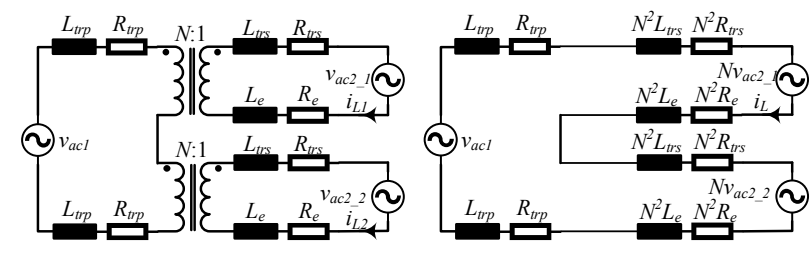

Fig. 3(a): Simplify the full-bridges

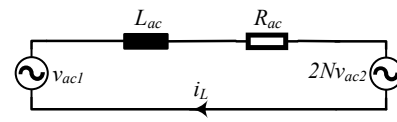

Fig. 3 (c): Combine all the circuit elements in series
Fig. 3 (b): Remove the transformer

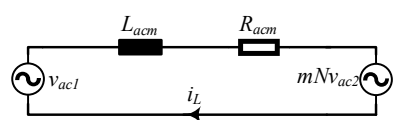

Fig. 4: Equivalent circuit of a $\mathrm{P}^{2} \mathrm{DAB}$ converter with multiple transformers

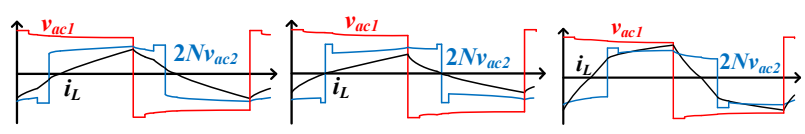

(a) Mode $a$

(b) Mode $b$

(c) Mode $c$

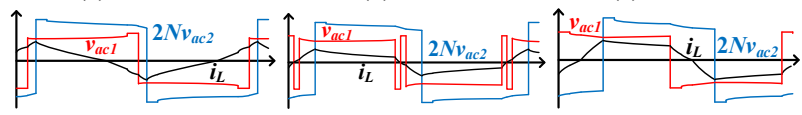

(d) Mode $d$

(e) Mode $e$

(f) Mode $f$

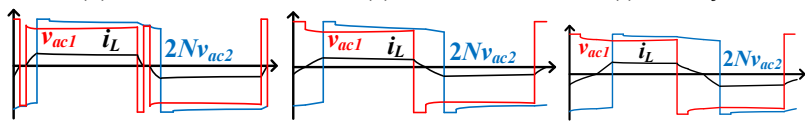

(g) Mode $g$

(h) Mode $h$

(i) Mode $i$

Fig. 5: Waveforms of $v_{a c 1}, v_{a c 2}$ and $i_{L}$ at different operation modes

$$
L_{a c}=2\left(L_{t r p}+N^{2} L_{t r s}+N^{2} L_{e}\right), R_{a c}=2\left(R_{t r p}+N^{2} R_{t r s}+N^{2} R_{e}\right)(3)
$$

For a $\mathrm{P}^{2} \mathrm{DAB}$ converter with multiple transformers, where the number of branches is $m$, the equivalent circuit can be directly drawn as in Fig. 4. The expressions of $L_{a c m}$ and $R_{a c m}$ are given in (4). The model can also be applied to a DAB converter with SPSM by equaling $m$ to 1 .

$$
L_{a c m}=m\left(L_{t r p}+N^{2} L_{t r s}+N^{2} L_{e}\right), R_{a c m}=m\left(R_{t r p}+N^{2} R_{t r s}+N^{2} R_{e}\right) \text { (4) }
$$

After deriving the equivalent circuit, the possible circuit operation modes need to be specified. The modes addressed in this paper for the $\mathrm{P}^{2} \mathrm{DAB}$ converter are the same as those determined in [8]. However, due to the consideration of the parasitic elements, the shape of the waveforms of $v_{a c l}, 2 N v_{a c 2}$ and $i_{L}$ changes. Especially with the use of $\mathrm{GaN}$ devices, whose free-wheeling voltage drop is much larger than Silicon devices. Therefore, the waveforms of $v_{a c 1}, 2 N v_{a c 2}$ and $i_{L}$ at different operation modes need modifications. The modified waveforms for $V_{1} \rightarrow V_{2}$ are given in Fig. 5. The operation conditions for Mode $a \sim$ Mode $i$ in Fig. 5 are summarized in Table I. The waveforms for $V_{2} \rightarrow V_{l}$ are of the same pattern as in Fig. 5, therefore are not given in this paper.

TABLE I: OPERATION CONDITIONS FOR DIFFERENT MODES

\begin{tabular}{cc}
\hline Mode & Operation Conditions \\
\hline$a$ & $V_{l}>2 N V_{2}, i_{L}$ changes direction after the dead time of the LVFB \\
$b$ & $V_{l}>2 N V_{2}, i_{L}$ changes direction during the dead time of the LVFB \\
$c$ & $V_{l}>2 N V_{2}, i_{L}$ changes direction before the dead time of the LVFB \\
$d$ & $V_{l}<2 N V_{2}, i_{L}$ changes direction before the dead time of the HVFB \\
$e$ & $V_{l}<2 N V_{2}, i_{L}$ changes direction during the dead time of the HVFB \\
$f$ & $V_{l}<2 N V_{2}, i_{L}$ changes direction after the dead time of the HVFB \\
$g$ & $V_{l} \approx 2 N V_{2}, i_{L}$ decreases to zero during the dead time of the HVFB \\
$h$ & $V_{l} \approx 2 N V_{2}, i_{L}$ decreases to zero at the end of the dead time of the HVFB \\
$i$ & $V_{l} \approx 2 N V_{2}, i_{L}$ decreases to zero after the dead time of the HVFB \\
\hline
\end{tabular}

With the waveforms and the equivalent circuit, the improved power flow model of the $\mathrm{P}^{2} \mathrm{DAB}$ converter can be derived. Power flow equations of the $\mathrm{P}^{2} \mathrm{DAB}$ converter with SPSM in all of the 9 modes under both of the two power flow directions are given in the appendix.

\section{SIMULATIONS}

Fig. 6 depicts both the calculated power of the $\mathrm{P}^{2} \mathrm{DAB}$ converter by the lossless model and the simulated ones by Matlab with PLECS Blockset. Parameters used in the calculations and the simulations are given in Table II. As shown, the calculations and simulations are well matched. The derived lossless model is thereby valid.

TABLE II: PARAMETERS USED IN THE CALCULATIONS AND THE SIMULATIONS TO VERIFY THE LOSSLESS MODEL

\begin{tabular}{llllllll}
\hline$V_{l}$ & $600 \mathrm{~V}$ & $V_{2}$ & $60 \mathrm{~V}$ & $N$ & 4 & $f_{s}$ & $300 \mathrm{kHz}$ \\
$L_{e}$ & $500 \mathrm{nH}$ & $V_{d H}$ & $3.8 \mathrm{~V}$ & $V_{d L}$ & $2.5 \mathrm{~V}$ & $R_{\text {onH }}$ & $65 \mathrm{~m} \Omega$ \\
$R_{\text {on } L}$ & $3 \mathrm{~m} \Omega$ & $R_{e}$ & $3 \mathrm{~m} \Omega$ & $R_{t r p}$ & $1.8 \Omega$ & $R_{t r s}$ & $80 \mathrm{~m} \Omega$ \\
$L_{l k p}$ & $2.5 \mathrm{uH}$ & $L_{l k s}$ & $110 \mathrm{nH}$ & $T_{d}$ & $120 \mathrm{~ns}$ & & \\
\hline
\end{tabular}




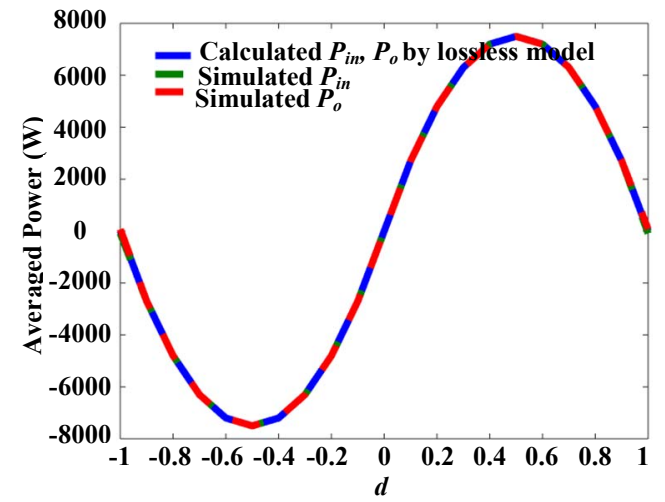

Fig. 6: Calculated power flow characteristics of the $\mathrm{P}^{2} \mathrm{DAB}$ converter by the lossless model and the corresponded simulations
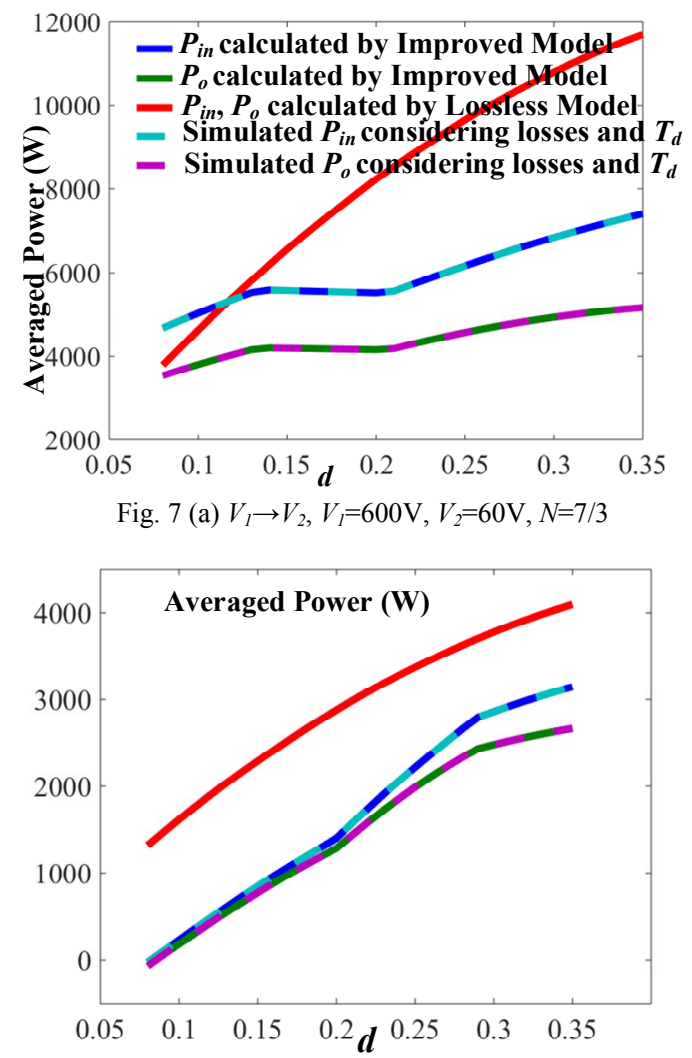

Fig. 7 (b) $V_{l} \rightarrow V_{2}, V_{l}=600 \mathrm{~V}, V_{2}=60 \mathrm{~V}, N=20 / 3$

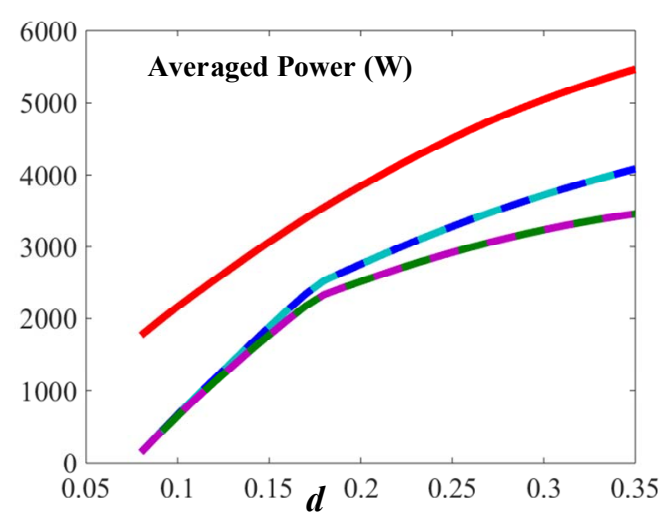

Fig. 7 (c) $V_{l} \rightarrow V_{2}, V_{I}=601 \mathrm{~V}, V_{2}=60 \mathrm{~V}, N=15 / 3$

Fig. 7 gives both the calculated power of the $\mathrm{P}^{2} \mathrm{DAB}$ converter by the improved model and the simulated ones by Matlab with PLECS Blockset. The calculated power flow characteristics by the lossless model are also given in Fig. 7 for comparison.

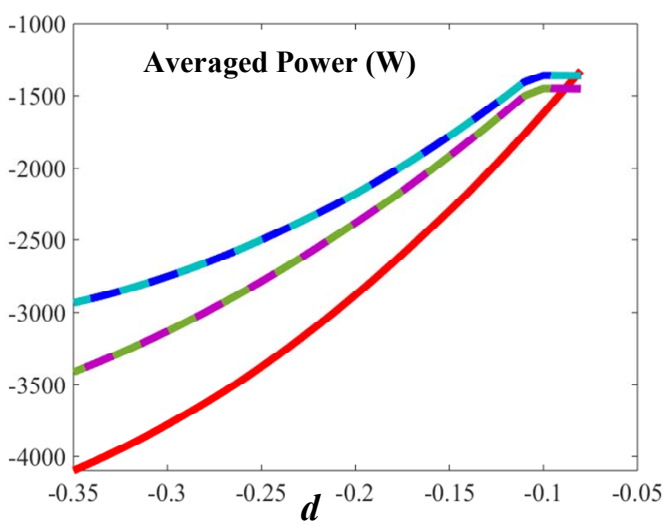

Fig. 7 (d) $V_{2} \rightarrow V_{l}, V_{l}=600 \mathrm{~V}, V_{2}=60 \mathrm{~V}, N=20 / 3$

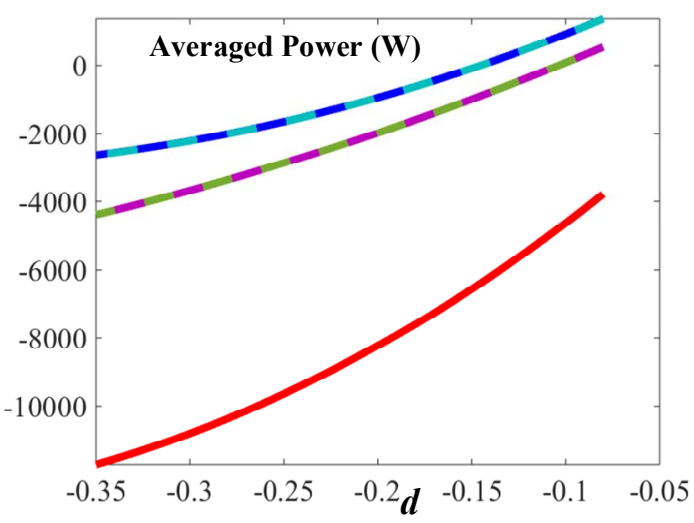

Fig. 7 (e) $V_{2} \rightarrow V_{l}, V_{l}=600 \mathrm{~V}, V_{2}=60 \mathrm{~V}, N=7 / 3$

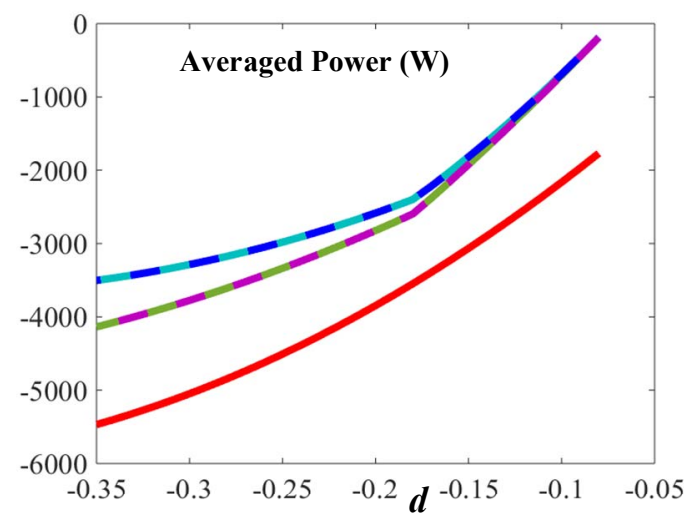

Fig. 7 (f) $V_{2} \rightarrow V_{l}, V_{l}=601 \mathrm{~V}, V_{2}=60 \mathrm{~V}, N=15 / 3$

Fig. 7: Calculated power flow characteristics of the $\mathrm{P}^{2} \mathrm{DAB}$ converter by the improved model and the corresponded simulations

The absolute value of $d$ in both calculations and simulations is limited to 0.35 because the phase shift angle is usually limited to small values (below $\pi / 4$ ) to suppress the reactive losses in high-power applications. And a limited maximum $d$ also helps reduce the simulation time.

As shown in Fig. 7, the calculated power by the improved model match the simulations well for all modes at both power flow directions. Therefore the improved power flow model is valid. Regarding the power flow characteristics, the improved model provides more details about the power flow than the lossless model. For this reason, the improved model is more suitable for investigating the power flow characteristics of the $\mathrm{P}^{2} \mathrm{DAB}$ converter. 


\section{EXPERIMENTS}

A GaN $\mathrm{P}^{2} \mathrm{DAB}$ prototype is built to investigate the accuracy of the two models. Key components used in the prototype are given in Table III. Fig. 9 shows a picture of the prototype. Fig. 10 compares the calculated $P_{\text {in }}$ and $P_{o}$ by both of the two models with the experimental results $\left(V_{l}=180 \mathrm{~V}, V_{2}=15 \mathrm{~V}, L_{e}=500 \mathrm{nH}, N=4\right)$. As shown, both models have errors. The lossless model is more accurate at small $d$ region, while the improved one is more accurate at medium and large $d$ region. Moreover, the calculated power flow characteristics by the improved model shifted to the left down side of the tested power flow characteristics. The cause of this shift is the output capacitance of the switches. In the improved model, this capacitance is ignored, the rate of change of the switching node voltage during switching is considered to be infinite. However, as shown in Fig. 11, the experimental switching node voltage changes slowly during switching due to the output capacitance and the low-power operation. Therefore, the improved model shows low accuracy at the low power range. In order to obtain a high accuracy over the entire power range, the influence of the output capacitance of the switches need to be considered.

Also from Fig. 10, at specific $d$ ranges, the tested averaged power decreases or nearly keeps unchanged when $d$ increases. This so-called power plateau phenomenon addressed in [9] also exists in the $\mathrm{P}^{2} \mathrm{DAB}$ converter with SPSM, and it is only predicted by the improved model as shown in Fig. 7(a) and Fig. 7(d).

TABLE III: KEY COMPONENTS LIST

\begin{tabular}{cc}
\hline HV side GaN HEMT & GS66516B \\
LV side GaN HEMT & EPC2021 \\
Transformer & ELP64/10/50, N97, PCB winding \\
Inductor & ELP43/10/28, N97, PCB winding \\
\hline
\end{tabular}

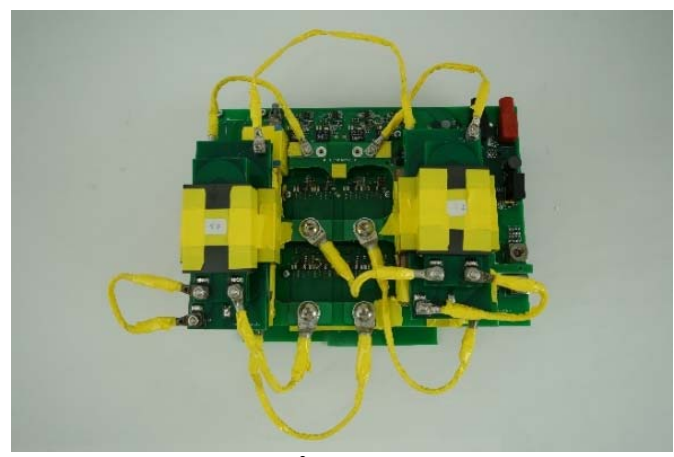

Fig. 9: $\mathrm{P}^{2} \mathrm{DAB}$ prototype

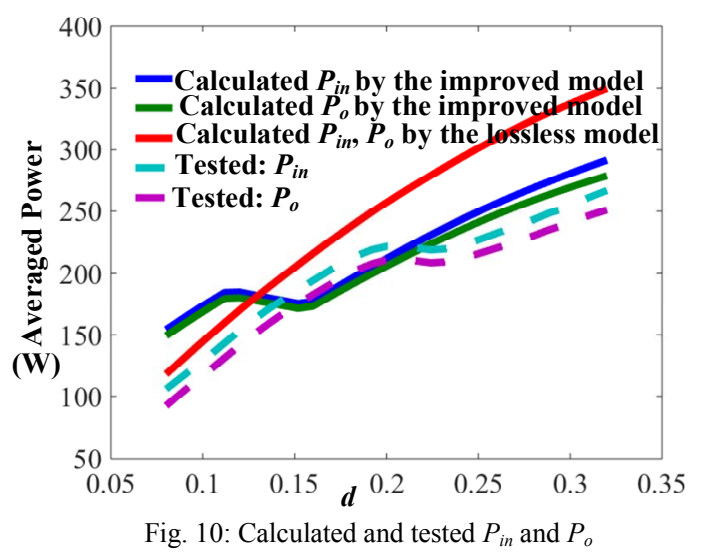

Fig. 10: Calculated and tested $P_{\text {in }}$ and $P_{o}$

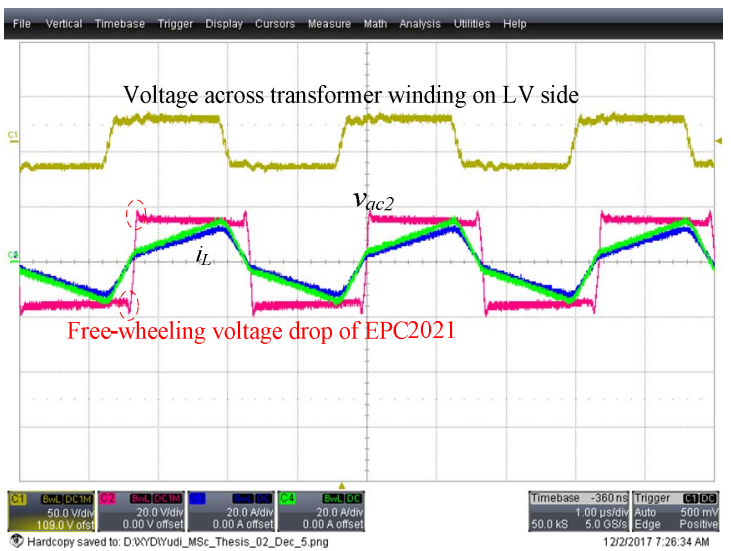

Fig. 11: Measured key waveforms of the prototype

\section{CONCLUSIONS AND FUTURE WORK}

A lossless power flow model and an improved power flow model for the $\mathrm{P}^{2} \mathrm{DAB}$ converter with single-phaseshift modulation are derived. The improved model considers the dead time and the conduction losses of the switches and the magnetic components. Both models are compared with the experimental results. The lossless model is more accurate at small phase shift region, while the improved one is more accurate at medium and large phase shift region. In order to achieve high accuracy over the entire phase shift range, the output capacitance of the switches should be considered in the future work. And it is also proved that the improved model provides more details about the power flow characteristics of the $\mathrm{P}^{2} \mathrm{DAB}$ converter.

\section{REFERENCES}

[1] B. Li, F. C. Lee, Q. Li, Z. Y. Liu, "Bi-directional onboard charger architecture and control for achieving ultrahigh efficiency with wide battery voltage range," IEEE Applied Power Electronics Conference and Exposition (APEC), pp. 3688-3694, Mar. 2017.

[2] R. M. Burkart, J. W. Kolar, "Comparative $\eta-\rho-\sigma$ pareto optimization of $\mathrm{Si}$ and $\mathrm{SiC}$ multilevel Dual-ActiveBridge topologies with wide input voltage range," IEEE Trans. Power Electronics, vol. 32, no. 7, pp. 5258-5270, Jul. 2017.

[3] F. Xue, R. Y. Yu, A. Q. Huang, "A 98.3\% efficient $\mathrm{GaN}$ isolated bidirectional DC-DC converter for DC Microgrid energy storage system applications", IEEE Trans. Industrial Electronics, vol. 64, no. 11, pp. $9094-$ 9103, Mar. 2017.

[4] R. W. A. A. De Doncker, D. M. Divan, M. H. Kheraluwala, "A three-phase soft-switched high-powerdensity $\mathrm{dc} / \mathrm{dc}$ converter for high-power applications," IEEE Trans. Industrial Applications, vol. 27, no. 1, pp. 63-73, Jan/Feb. 1991.

[5] B. Zhao, Q. Song, J. G. Li, X. P. Xu, W. H. Liu, "Comparative analysis of multilevel-high-frequency-link and multilevel-dc-link DC-DC transformers based on MMC and Dual-Active bridge for MVDC application," IEEE Trans. Power Electronics, vol. 33, no. 3, pp. 20352049, Mar. 2018.

[6] B. Zhao, Q. Song, J. G. Li, Q. H. Sun, W. H. Liu, "Full-process operation, control, and experiments of modular high-frequency-link DC transformer based on 
dual active bridge for flexible MVDC distribution," IEEE Trans. Power Electronics, vol. 32, no. 9, pp. 6751-6766, Sept. 2017.

[7] Z. Zhang, K. Tomas-Manez, Y. D. Xiao, M. A. E. Andersen, "High voltage gain dual active bridge converter with an extended operation range for renewable energy systems", IEEE Applied Power Electronics Conference and Exposition (APEC), Mar. 2018.

[8] B. Zhao, Q. Song, W. H. Liu, Y. D. Sun, "Dead time effect of the high frequency isolated bidirectional full bridge dc-dc converter: comprehensive theoretical analysis and experimental verification", IEEE Transactions on Power Electronics, vol. 29, No. 4, 2014: $1667-1680$

[9] Y. D. Xiao, Z. Zhang, K. Tomas-Manez, M. A. E. Andersen, "Power Plateau and Anti-Power Phenomenon of Dual Active Bridge Converter with Phase-Shift Modulation", IEEE Applied Power Electronics Conference and Exposition (APEC), Mar. 2018.

\section{APPENDIX}

The following are the power flow equations of the improved model for the $\mathrm{P}^{2} \mathrm{DAB}$ converter with SPSM. Since the equations of current integrations are of the same form for all of the operation conditions, they are only given once as in (3).

(3) $V_{1} \rightarrow V_{2}$, Mode $a$ :

$$
\begin{aligned}
& \text { Condition: } V_{1}>2 N V_{2} \wedge d>2 T_{d} f_{s} \wedge i_{L}\left(t_{3}\right) \leq 0 \\
& P_{\text {in }}=2 V_{1} f_{s}\left(I n t_{1}+I n t_{2}+I n t_{3}+I n t_{4}+I n t_{5}\right) \\
& P_{o}=2 V_{2} \cdot 2 N f_{s}\left(I n t_{1}+I n t_{2}+I n t_{3}+I n t_{4}+I n t_{5}\right) \\
& \operatorname{Int} t_{1}=M_{1} \Delta t_{1}+\left[i_{L}\left(t_{0}\right)-M_{1}\right]\left(-\frac{1}{J_{1}}\right)\left(e^{-J_{1} \Delta \Delta_{1}}-1\right), \operatorname{In} t_{2}=M_{2} \Delta t_{2}+\left[i_{L}\left(t_{1}\right)-M_{2}\right]\left(-\frac{1}{J_{2}}\right)\left(e^{-J_{2} \Delta t_{2}}-1\right) \\
& \operatorname{Int} t_{3}=M_{3} \Delta t_{3}+\left[i_{L}\left(t_{2}\right)-M_{3}\right]\left(-\frac{1}{J_{3}}\right)\left(e^{-J_{3} \Delta t_{3}}-1\right), \operatorname{Int} t_{4}=M_{4} \Delta t_{4}+\left[i_{L}\left(t_{3}\right)-M_{4}\right]\left(-\frac{1}{J_{4}}\right)\left(e^{-J_{4} \Delta_{4}}-1\right) \\
& \left\{\operatorname{Int}_{5}=M_{5} \Delta t_{5}+\left[i_{L}\left(t_{4}\right)-M_{5}\right]\left(-\frac{1}{J_{5}}\right)\left(e^{-J_{s} \Delta t_{s}}-1\right), \Delta t_{1}=T_{d}, \Delta t_{2}=\frac{d}{2 f_{s}}-T_{d}, \Delta t_{3}=T_{d}, \Delta t_{4}=\frac{1}{2 f_{s}}-\Delta t_{1}-\Delta t_{2}-\Delta t_{3}-\Delta t_{5}\right.
\end{aligned}
$$

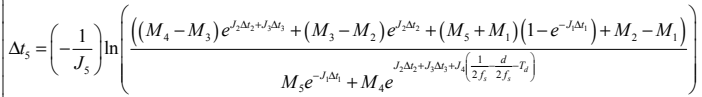

$$
\begin{aligned}
& J_{1}=\frac{R_{a c}+4 N^{2} R_{o n L}}{L_{a c}}, J_{2}=\frac{R_{a c}+2 R_{o n H}+4 N^{2} R_{o n L}}{L_{a c}}, J_{3}=\frac{R_{a c}+2 R_{o n H}}{L_{a c}}, J_{4}=\frac{R_{a c}+2 R_{o n H}+4 N^{2} R_{o n L}}{L_{a c}} \\
& J_{5}=\frac{R_{a c}+2 R_{o n H}+4 N^{2} R_{o n L}}{L_{a c}}, M_{1}=\frac{V_{1}+2 V_{d H}+2 N V_{2}}{R_{a c}+4 N^{2} R_{o n L}}, M_{2}=\frac{V_{1}+2 N V_{2}}{R_{a c}+2 R_{o n H}+4 N^{2} R_{o n L}}, M_{3}=\frac{V_{1}+2 N\left(V_{2}+2 V_{a L}\right)}{R_{a c}+2 R_{o n H}} \\
& M_{4}=\frac{V_{1}-2 N V_{2}}{R_{\text {ac }}+2 R_{\text {ouH }}+4 N^{2} R_{\text {ouI }}}, M_{5}=\frac{V_{1}-2 N V_{2}}{R_{\text {oc }}+2 R_{\text {ouH }}+4 N^{2} R_{\text {out }}}
\end{aligned}
$$

(4) $V_{l} \rightarrow V_{2}$, Mode $b$ :

$$
\begin{aligned}
& \text { Condition: } V_{1}>2 N V_{2} \wedge d>2 T_{d} f_{s} \wedge i_{L}\left(t_{P b 2}\right)<0 \wedge i_{L}\left(t_{P b 4}\right)>0 \\
& P_{i n}=2 V_{1} f_{s}\left(I t_{P b 1}+\operatorname{Int}_{P b 2}+\operatorname{Int}_{P b 3}+\operatorname{Int}_{P b 4}+\operatorname{Int}_{P b 5}\right) \\
& P_{o}=2 V_{2} \cdot 2 N f_{s}\left(-I n t_{P b 1}-I n t_{P b 2}-I n t_{P b 3}+I n t_{P b 4}+I n t_{P b 5}\right) \\
& \Delta t_{p b 1}=T_{d}, \Delta t_{p b 2}=\frac{d}{2 f_{s}}-T_{d}, \Delta t_{p b 3}=T_{d}-\Delta t_{p b 4}, \Delta t_{p b 5}=\frac{1}{2 f_{s}}-\Delta t_{p b 1}-\Delta t_{p b 2}-\Delta t_{p b 3}-\Delta t_{p b 4}
\end{aligned}
$$

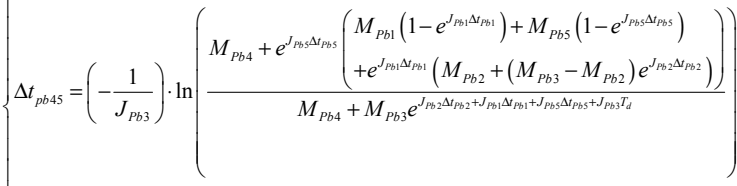

$$
\begin{aligned}
& J_{p b 1}=\frac{R_{a c}+4 N^{2} R_{o n L}}{L_{a c}}, J_{p b 2}=\frac{R_{a c}+2 R_{o n H}+4 N^{2} R_{o n L}}{L_{a c}}, J_{p b 3}=\frac{R_{a c}+2 R_{o n H}}{L_{a c}}, J_{p b 4}=\frac{R_{a c}+2 R_{o n H}}{L_{a c}} \\
& J_{p b 5}=\frac{R_{a c}+2 R_{o n H}+4 N^{2} R_{o n L}}{L_{a c}}, M_{p b 1}=\frac{V_{1}+2 V_{d H}+2 N V_{2}}{R_{a c}+4 N^{2} R_{o n L}}, M_{p b 2}=\frac{V_{1}+2 N V_{2}}{R_{a c}+2 R_{o n H}+4 N^{2} R_{o n L}} \\
& M_{p b 3}=\frac{V_{1}+2 N\left(V_{2}+2 V_{d L}\right)}{R_{a c}+2 R_{o n H}}, M_{p b 4}=\frac{V_{1}-2 N\left(V_{2}+2 V_{d L}\right)}{R_{a c}+2 R_{o n H}}, M_{p b 5}=\frac{V_{1}-2 N V_{2}}{R_{a c}+2 R_{o n H}+4 N^{2} R_{o n L}}
\end{aligned}
$$

(5) $V_{l} \rightarrow V_{2}$, Mode $c$

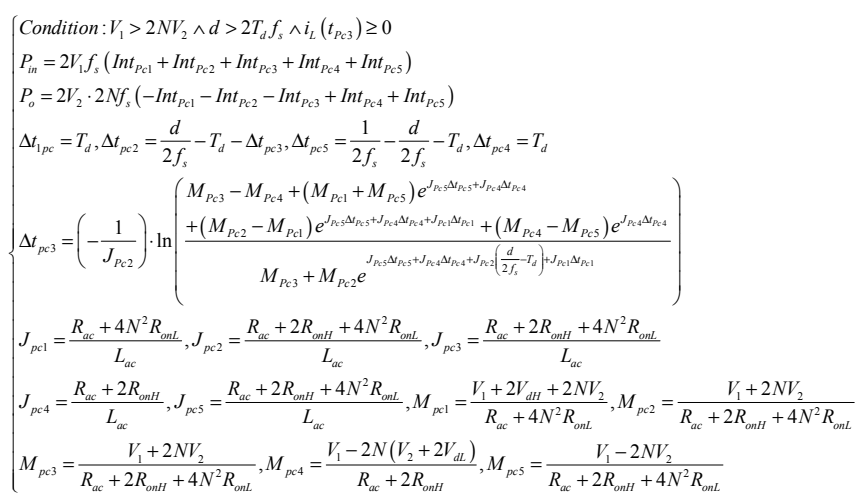

(6) $V_{l} \rightarrow V_{2}$, Mode $d$ :

$$
\begin{aligned}
& \text { Condition: } V_{1}<2 N V_{2} \wedge d>2 T_{d} f_{s} \wedge i_{L}\left(t_{P d 0}\right) \geq 0 \\
& P_{i n}=2 V_{1} f_{s}\left(-I n t_{P d 1}+I n t_{P d 2}+I n t_{P d 3}+I n t_{P d 4}+I n t_{P d 5}\right) \\
& P_{o}=2 V_{1} f_{s}\left(-I n t_{P d 1}+I n t_{P d 2}+I n t_{P d 3}+I n t_{P d 4}+I n t_{P d 5}\right) \\
& \Delta t_{p d 1}=T_{d}, \Delta t_{p d 2}=\frac{d}{2 f_{s}}-T_{d}, \Delta t_{p d 3}=T_{d}, \Delta t_{p d 5}=\frac{1}{2 f_{s}}-\frac{d}{2 f_{s}}-T_{d}-\Delta t_{P d 4}
\end{aligned}
$$

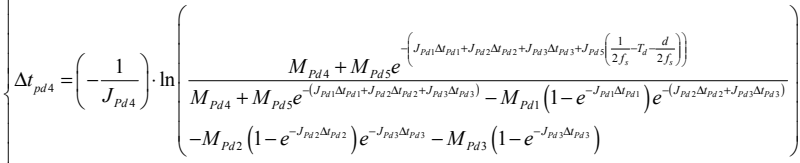

$$
\begin{aligned}
& J_{p d 1}=\frac{R_{a c}+4 N^{2} R_{o n L}}{L_{a c}}, J_{p d 2}=\frac{R_{a c}+2 R_{o n H}+4 N^{2} R_{o n L}}{L_{a c}}, J_{p d 3}=\frac{R_{a c}+2 R_{o n H}}{L_{a c}}, J_{p d 4}=\frac{R_{a c}+2 R_{o n H}+4 N^{2} R_{o n L}}{L_{a c}} \\
& J_{p d 5}=\frac{R_{a c}+2 R_{o n H}+4 N^{2} R_{o n L}}{L_{a c}}, M_{p d 1}=\frac{-\left(V_{1}+2 V_{d H}\right)+2 N V_{2}}{R_{a c}+4 N^{2} R_{o n L}}, M_{p d 2}=\frac{V_{1}+2 N V_{2}}{R_{a c}+2 R_{o n H}+4 N^{2} R_{o n L}} \\
& M_{p d 3}=\frac{V_{1}-2 N\left(V_{2}+2 V_{d L}\right)}{R_{a c}+2 R_{o n H}}, M_{p d 4}=\frac{V_{1}-2 N V_{2}}{R_{a c}+2 R_{o n H}+4 N^{2} R_{o n L}}, M_{p d s}=\frac{V_{1}-2 N V_{2}}{R_{a c}+2 R_{o n H}+4 N^{2} R_{o n L}}
\end{aligned}
$$

(7) $V_{1} \rightarrow V_{2}$, Mode $e$ :

$$
\begin{aligned}
& \text { Condition: } V_{1}<2 N V_{2} \wedge d>2 T_{d} f_{s} \wedge i_{L}\left(t_{P e 0}\right)<0 \wedge i_{L}\left(t_{P e 2}\right)>0 \\
& P_{\text {in }}=2 V_{1} f_{s}\left(\operatorname{Int}_{P e 1}-\operatorname{Int}_{P e 2}+\operatorname{Int}_{P e 3}+\operatorname{Int}_{P e 4}+\operatorname{Int}_{P e 5}\right) \\
& P_{o}=2 V_{2} \cdot 2 N f_{s}\left(-I n t_{P e 1}-I n t_{P e 2}-I n t_{P e 3}+I n t_{P e 4}+I n t_{P e}\right) \\
& \Delta t_{p e 2}=T_{d}-\Delta t_{P e 1}, \Delta t_{p e 3}=\frac{d}{2 f_{s}}-T_{d}, \Delta t_{p e 4}=T_{d}, \Delta t_{p e 5}=\frac{1}{2 f_{s}}-\frac{d}{2 f_{s}}-T_{d}
\end{aligned}
$$

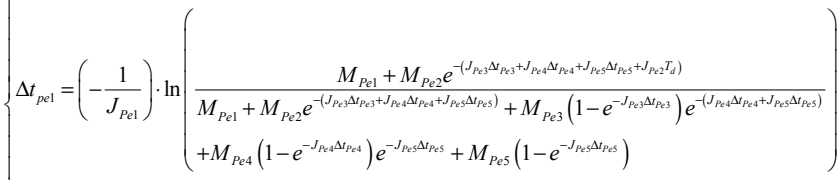

$$
\begin{aligned}
& J_{p e 1}=\frac{R_{a c}+4 N^{2} R_{o n L}}{L_{a c}}, J_{p e 2}=\frac{R_{a c}+4 N^{2} R_{o n L}}{L_{a c}}, J_{p e 3}=\frac{R_{a c}+2 R_{o n H}+4 N^{2} R_{o n L}}{L_{a c}}, J_{p e 4}=\frac{R_{a c}+2 R_{o n H}}{L_{a c}} \\
& J_{p e 5}=\frac{R_{a c}+2 R_{o n H}+4 N^{2} R_{o n L}}{L_{a c}}, M_{p e 1}=\frac{V_{1}+2 V_{d H}+2 N V_{2}}{R_{a c}+4 N^{2} R_{o n L}}, M_{p e 2}=\frac{-\left(V_{1}+2 V_{d H}\right)+2 N V_{2}}{R_{a c}+4 N^{2} R_{o n L}} \\
& M_{p e 3}=\frac{V_{1}+2 N V_{2}}{R_{a c}+2 R_{o n H}+4 N^{2} R_{o n L}}, M_{p e 4}=\frac{V_{1}-2 N\left(V_{2}+2 V_{d L}\right)}{R_{a c}+2 R_{o n H}}, M_{p e 5}=\frac{V_{1}-2 N V_{2}}{R_{a c}+2 R_{o n H}+4 N^{2} R_{o n L}}
\end{aligned}
$$

(8) $V_{l} \rightarrow V_{2}$, Mode $f$ :

$$
\begin{aligned}
& \text { Condition: } V_{1}<2 N V_{2} \wedge d>2 T_{d} f_{s} \wedge i_{L}\left(t_{P f 1}\right) \leq 0 \\
& P_{i n}=2 V_{1} f_{s}\left(I n t_{P f 1}+I n t_{P f 2}+I n t_{P f 3}+I n t_{P f 4}+I n t_{P f 5}\right) \\
& P_{o}=2 V_{2} \cdot 2 N f_{s}\left(-I n t_{P f 1}-I n t_{P f 2}-I n t_{P f 3}+I n t_{P f 4}+I n t_{P f 5}\right) \\
& \Delta t_{p f 1}=T_{d}, \Delta t_{2}=\frac{d}{2 f_{s}}-T_{d}, \Delta t_{p f 3}=\frac{d}{2 f_{s}}-T_{d}-\Delta t_{p f 2}, \Delta t_{p f 4}=T_{d}, \Delta t_{p f 5}=\frac{1}{2 f_{s}}-\frac{d}{2 f_{s}}-T_{d}
\end{aligned}
$$

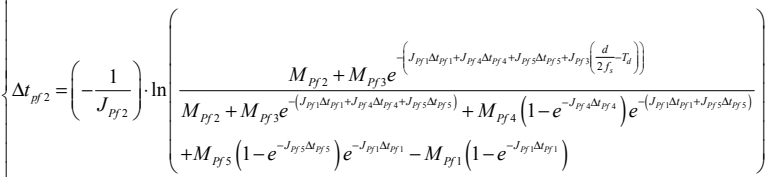

$$
\begin{aligned}
& \left\{\begin{array}{l}
J_{p f 1}=\frac{R_{a c}+4 N^{2} R_{o n L}}{L_{a c}}, J_{p f 2}=\frac{R_{a c}+2 R_{o n H}+4 N^{2} R_{o n L}}{L_{a c}}, J_{p f 3}=\frac{R_{a c}+2 R_{o n H}+4 N^{2} R_{o n L}}{L_{a c}}, J_{p f 4}=\frac{R_{a c}+2 R_{o n H}}{L_{a c}} \\
J_{p f 5}=\frac{R_{a c}+2 R_{o n H}+4 N^{2} R_{o n L}}{L_{a c}}, M_{p f 1}=\frac{V_{1}+2 V_{d H}+2 N V_{2}}{R_{a c}+4 N^{2} R_{o n L}}, M_{p f 2}=\frac{V_{1}+2 N V_{2}}{R_{a c}+2 R_{o n H}+4 N^{2} R_{o n L}} \\
M_{p f 3}=\frac{V_{1}+2 N V_{2}}{R_{a c}+2 R_{o n H}+4 N^{2} R_{o n L}}, M_{p f 4}=\frac{V_{1}-2 N\left(V_{2}+2 V_{d L}\right)}{R_{a c}+2 R_{o n H}}, M_{p f 5}=\frac{V_{1}-2 N V_{2}}{R_{a c}+2 R_{o n H}+4 N^{2} R_{o n L}}
\end{array}\right.
\end{aligned}
$$

(9) $V_{l} \rightarrow V_{2}$, Mode $g$ : 


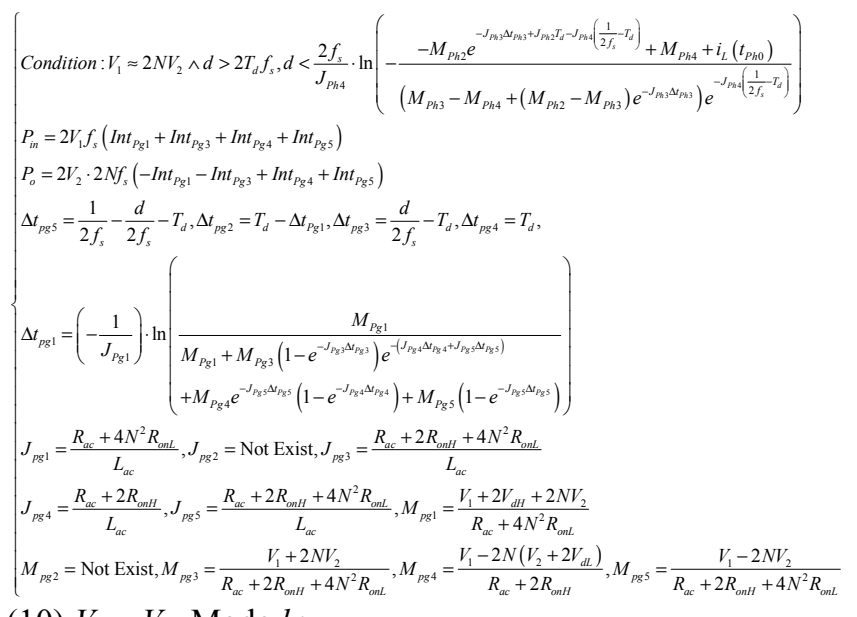

(10) $V_{l} \rightarrow V_{2}$, Mode $h$ :

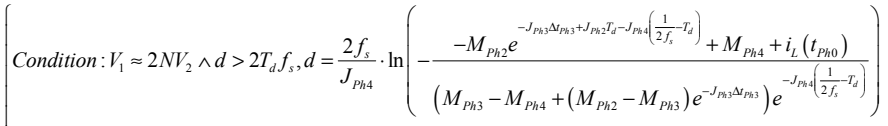

$$
\begin{aligned}
& P_{i n}=2 V_{1} f_{s}\left(I n t_{P h 1}+I n t_{P h 2}+\operatorname{Int} t_{P h 3}+\operatorname{Int} t_{P h 4}\right) \\
& P_{o}=2 V_{2} \cdot 2 N f_{s}\left(-I n t_{P h 1}-I n t_{P h 2}+I n t_{P h 3}+I n t_{P h 4}\right) \\
& \Delta t_{p h 1}=T_{d}, \Delta t_{p h 2}=\frac{d}{2 f_{s}}-T_{d}, \Delta t_{p h 3}=T_{d}, \Delta t_{p h 4}=\frac{1}{2 f_{s}}-\frac{d}{2 f_{s}}-T_{d}, \Delta t_{p h 5}=0 \\
& \left\{J_{p h 1}=\frac{R_{a c}+4 N^{2} R_{o n L}}{L_{a c}}, J_{p h 2}=\frac{R_{a c}+2 R_{o n H}+4 N^{2} R_{o n L}}{L_{a c}}, J_{p h 3}=\frac{R_{a c}+2 R_{o n H}}{L_{a c}}\right. \\
& J_{p h 4}=\frac{R_{a c}+2 R_{o n H}+4 N^{2} R_{o n L}}{L_{a c h}}, J_{p h s}=\text { Not Exist } \\
& M_{p h 1}=\frac{V_{1}+2 V_{d H}+2 N V_{2}}{R_{a c}+4 N^{2} R_{o n L}}, M_{p h 2}=\frac{V_{1}+2 N V_{2}}{R_{a c}+2 R_{o n H}+4 N^{2} R_{o n L}}, M_{p h 3}=\frac{V_{1}-2 N\left(V_{2}+2 V_{d L}\right)}{R_{a c}+2 R_{o n H}} \\
& M_{p h 4}=\frac{V_{1}-2 N V_{2}}{R_{a c}+2 R_{o n H}+4 N^{2} R_{o n L}}, M_{p h 5}=\text { Not Exist }
\end{aligned}
$$

(11) $V_{l} \rightarrow V_{2}$, Mode $i$ :

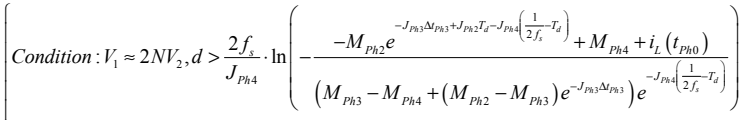

$$
\begin{aligned}
& P_{\text {in }}=-2 V_{1} f_{s}\left(-\operatorname{Int} t_{P b 1}-\operatorname{Int}_{P b 2}-\operatorname{Int}_{P b 3}+\operatorname{Int}_{P b 4}+\operatorname{Int}_{P b 5}\right) \\
& P_{o}=-2 V_{2} \cdot 2 N f_{s}\left(I n t_{P b 1}+I n t_{P b 2}+I n t_{P b 3}+I n t_{P b 4}+I n t_{P b 5}\right) \\
& \Delta t_{p i 1}=T_{d}, \Delta t_{p i 3}=\frac{d}{2 f_{s}}-T_{d}-\Delta t_{P i 2}, \Delta t_{p i 4}=T_{d}, \Delta t_{p i 5}=\frac{1}{2 f_{s}}-\frac{d}{2 f_{s}}-T_{d}
\end{aligned}
$$

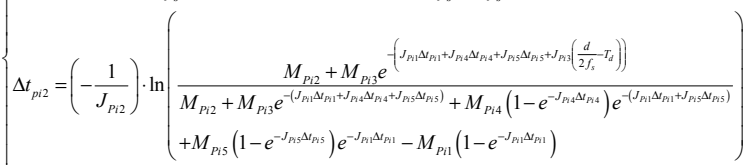

$$
\begin{aligned}
& J_{p i 1}=\frac{R_{a c}+4 N^{2} R_{o n L}}{L_{a c}}, J_{p i 2}=\frac{R_{a c}+2 R_{o n H}+4 N^{2} R_{o n L}}{L_{a c}}, J_{p i 3}=\frac{R_{a c}+2 R_{o n H}+4 N^{2} R_{o n L}}{L_{a c}} \\
& J_{p i 4}=\frac{R_{a c}+2 R_{o n H}}{L_{a c}}, J_{p i 5}=\frac{R_{a c}+2 R_{o n H}+4 N^{2} R_{o n L}}{L_{a c}}, M_{p i 1}=\frac{V_{1}+2 V_{d H}+2 N V_{2}}{R_{a c}+4 N^{2} R_{o n L}}, M_{p i 2}=\frac{V_{1}+2 N V_{2}}{R_{a c}+2 R_{o n H}+4 N^{2} R_{o n L}} \\
& M_{p i 3}=\frac{V_{1}+2 N V_{2}}{R_{a c}+2 R_{o n t}+4 N^{2} R_{o n L}}, M_{p i 4}=\frac{V_{1}-2 N\left(V_{2}+2 V_{a l l}\right)}{R_{a c}+2 R_{o n t}}, M_{p i s}=\frac{V_{1}-2 N V_{2}}{R_{a c}+2 R_{o u H}+4 N^{2} R_{o n L}}
\end{aligned}
$$

(12) $V_{2} \rightarrow V_{l}$, Mode $a$ :

$$
\begin{aligned}
& \text { Condition : } 2 N V_{2}>V_{1} \wedge-d>2 T_{d} f_{s} \wedge i_{L}\left(t_{N a 3}\right) \leq 0 \\
& P_{i n}=-2 V_{2} \cdot 2 N f_{s}\left(\text { Int }_{P b 1}+\operatorname{Int}_{P b 2}+\operatorname{Int}_{P b 3}+\operatorname{Int}_{P b 4}+\operatorname{Int}_{P b 5}\right) \\
& P_{o}=-2 V_{1} f_{s}\left(-I n t_{P b 1}-\operatorname{Int}_{P b 2}-\operatorname{Int}_{P b 3}+\operatorname{Int_{Pb4}}+\operatorname{Int}_{P b 5}\right) \\
& \Delta t_{n a 1}=T_{d}, \Delta t_{n a 2}=\frac{-d}{2 f_{s}}-T_{d}, \Delta t_{n a 3}=T_{d}, \Delta t_{n a 4}=\frac{1}{2 f_{s}}-\frac{-d}{2 f_{s}}-T_{d}-\Delta t_{N a 5} \\
& \left\{\Delta t_{n a 5}=\left(-\frac{1}{J_{N a 5}}\right) \ln \left(\frac{\left(\begin{array}{l}
\left(M_{N a 4}-M_{N a 3}\right) e^{J_{N a 2} \Delta_{N a 2}+J_{N a 3} \Delta_{N a b 3}}+\left(M_{N a 3}-M_{N a 2}\right) e^{J_{N a} \Delta_{N a 2}} \\
+\left(M_{N a 5}+M_{N a 1}\right)\left(1-e^{-J_{N a 1} \Delta_{N a 1}}\right)+M_{N a 2}-M_{N a 1}
\end{array}\right)}{\left.M_{N a 5} e^{-J_{N a 1} \Delta_{N a 1}}+M_{N a 4} e^{J_{N a 2} \Delta_{N a 2}+J_{N a 3} \Delta_{N a 3}+J_{N a a}\left(\frac{1}{2 f_{s}}-\frac{-d}{2 f_{s}}-T_{d}\right.}\right)}\right)\right. \\
& J_{n a 1}=\frac{R_{a c}+2 R_{o n H}}{L_{a c}}, J_{n a 2}=\frac{R_{a c}+2 R_{o n H}+4 N^{2} R_{o n L}}{L_{a c}}, J_{n a 3}=\frac{R_{a c}+4 N^{2} R_{o n L}}{L_{a c}}, J_{n a 4}=\frac{R_{a c}+2 R_{o n H}+4 N^{2} R_{o n L}}{L_{a c}} \\
& J_{n a s}=\frac{R_{a c}+2 R_{o n H}+4 N^{2} R_{o n L}}{L_{a c}}, M_{n a 1}=\frac{V_{1}+2 N\left(V_{2}+2 V_{a L}\right)}{R_{a c}+2 R_{o n H}}, M_{n a 2}=\frac{V_{1}+2 N V_{2}}{R_{a c}+2 R_{o n H}+4 N^{2} R_{o n L}} \\
& M_{n a 3}=\frac{V_{1}+2 V_{d H}+2 N V_{2}}{R_{a c}+4 N^{2} R_{o n L}}, M_{n a 4}=\frac{2 N V_{2}-V_{1}}{R_{a c}+2 R_{o n H}+4 N^{2} R_{\text {onL }}}, M_{n a 5}=\frac{2 N V_{2}-V_{1}}{R_{a c}+2 R_{o n H}+4 N^{2} R_{o n L}}
\end{aligned}
$$

(13) $V_{2} \rightarrow V_{l}$, Mode $b$ :

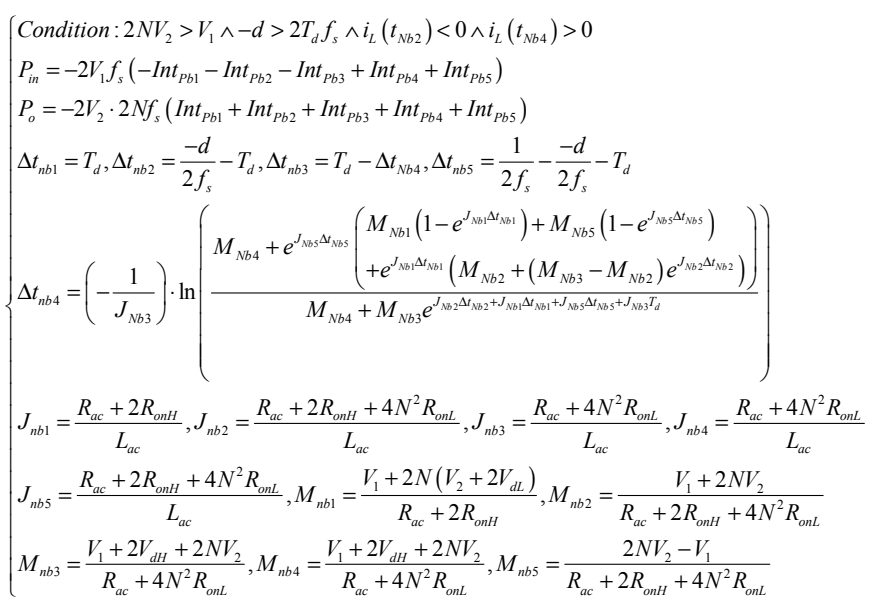

(14) $V_{2} \rightarrow V_{l}$, Mode $c$ :

$$
\begin{aligned}
& \text { Condition: } 2 N V_{2}>V_{1} \wedge-d>2 T_{d} f_{s} \wedge i_{L}\left(t_{N c 3}\right) \geq 0 \\
& P_{i n}=-2 V_{1} f_{s}\left(-I n t_{P C 1}-I n t_{P C 2}-I n t_{P_{C 3}}+\operatorname{Int}_{P_{C 4}}+\operatorname{Int} t_{P C 5}\right) \\
& P_{o}=-2 V_{2} \cdot 2 N f_{s}\left(\operatorname{Int}_{P C 1}+\operatorname{Int} t_{P C 2}+\operatorname{Int} t_{P C 3}+\operatorname{Int} t_{P C 4}+\operatorname{Int} t_{P C 5}\right) \\
& \Delta t_{n c 1}=T_{d}, \Delta t_{n c 2}=\frac{-d}{2 f_{s}}-T_{d}-\Delta t_{N c 3}, \Delta t_{n c 4}=T_{d}, \Delta t_{n c 5}=\frac{1}{2 f_{s}}-\frac{-d}{2 f_{s}}-T_{d}
\end{aligned}
$$

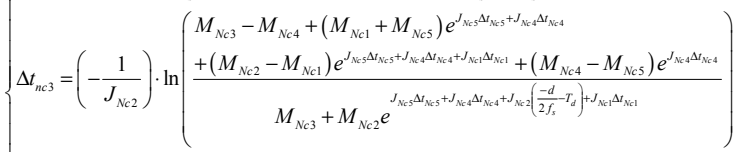

$$
\begin{aligned}
& J_{n c 1}=\frac{R_{a c}+2 R_{o n H}}{L_{a c}}, J_{n c 2}=\frac{R_{a c}+2 R_{o n H}+4 N^{2} R_{o n L}}{L_{a c}}, J_{n c 3}=\frac{R_{a c}+2 R_{o n H}+4 N^{2} R_{o n L}}{L_{a c}}, J_{n c 4}=\frac{R_{a c}+4 N^{2} R_{o n L}}{L_{a c}} \\
& J_{n c 5}=\frac{R_{a c}+2 R_{o n H}+4 N^{2} R_{o n L}}{L_{a c}}, M_{n c 1}=\frac{V_{1}+2 N\left(V_{2}+2 V_{d L}\right)}{R_{a c}+2 R_{o n H}}, M_{n c 2}=\frac{V_{1}+2 N V_{2}}{R_{a c}+2 R_{o n H}+4 N^{2} R_{o n L}} \\
& M_{n c 3}=\frac{V_{1}+2 N V_{2}}{R_{a c}+2 R_{o n H}+4 N^{2} R_{o n L}}, M_{n c 4}=\frac{2 N V_{2}-\left(V_{1}+2 V_{d H}\right)}{R_{a c}+4 N^{2} R_{o n L}}, M_{n c 5}=\frac{2 N V_{2}-V_{1}}{R_{a c}+2 R_{o n H}+4 N^{2} R_{o n L}}
\end{aligned}
$$

(15) $V_{2} \rightarrow V_{l}$, Mode $d$ :

$$
\begin{aligned}
& \text { Condition: } 2 N V_{2}<V_{1} \wedge-d>2 T_{d} f_{s} \wedge i_{L}\left(t_{N d 0}\right) \geq 0 \\
& P_{i n}=-2 V_{1} f_{s}\left(-I n t_{P d 1}-I n t_{P d 2}+\operatorname{Int} t_{P d 3}+I n t_{P d 4}+I n t_{P d 5}\right) \\
& P_{o}=-2 V_{2} \cdot 2 N f_{s}\left(-I n t_{P d 1}+I n t_{P d 2}+I n t_{P d 3}+I n t_{P d 4}+I n t_{P d 5}\right) \\
& \Delta t_{n d 1}=T_{d}, \Delta t_{n d 2}=\frac{-d}{2 f_{s}}-T_{d}, \Delta t_{n d 3}=T_{d}, \Delta t_{n d 5}=\frac{1}{2 f_{s}}-\frac{-d}{2 f_{s}}-T_{d}-\Delta t_{N d 4}
\end{aligned}
$$

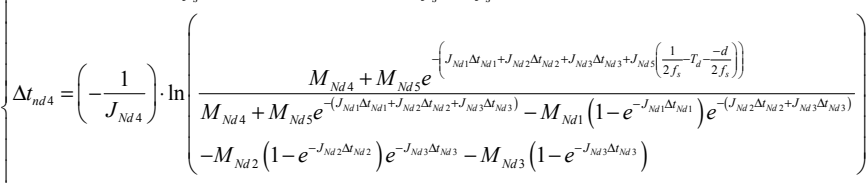

$$
\begin{aligned}
& J_{n d 1}=\frac{R_{a c}+2 R_{o n H}}{L_{a c}}, J_{n d 2}=\frac{R_{a c}+2 R_{o n H}+4 N^{2} R_{o n L}}{L_{a c}}, J_{n d 3}=\frac{R_{a c}+4 N^{2} R_{o n L}}{L_{a c}}, J_{n d 4}=\frac{R_{a c}+2 R_{o n H}+4 N^{2} R_{o n L}}{L_{a c}} \\
& J_{n d 5}=\frac{R_{a c}+2 R_{o n H}+4 N^{2} R_{o n L}}{L_{a c}}, M_{n d 1}=\frac{-2 N\left(V_{2}+2 V_{d L}\right)+V_{1}}{R_{a c}+2 R_{o n H}}, M_{n d 2}=\frac{V_{1}+2 N V_{2}}{R_{a c}+2 R_{o n H}+4 N^{2} R_{o n L}} \\
& M_{n d 3}=\frac{2 N V_{2}-\left(V_{1}+2 V_{d H}\right)}{R_{a c}+4 N^{2} R_{o n L}}, M_{n d 4}=\frac{2 N V_{2}-V_{1}}{R_{a c}+2 R_{o n H}+4 N^{2} R_{o n L}}, M_{n d 5}=\frac{2 N V_{2}-V_{1}}{R_{a c}+2 R_{o n H}+4 N^{2} R_{o n L}}
\end{aligned}
$$

(16) $V_{2} \rightarrow V_{1}$, Mode $e$ :

$$
\begin{aligned}
& \text { Condition: } 2 \mathrm{NV}_{2}<V_{1} \wedge-d>2 T_{d} f_{s} \wedge i_{L}\left(t_{\mathrm{Ne} 0}\right)<0 \wedge i_{L}\left(t_{\mathrm{Ne} 2}\right)>0 \\
& P_{i n}=-2 V_{1} f_{s}\left(-I n t_{P e 1}-\operatorname{Int}_{P e 2}-I n t_{P e 3}+I n t_{P e 4}+I n t_{P e 5}\right) \\
& P_{o}=-2 V_{2} \cdot 2 N f_{s}\left(\operatorname{Int}_{P e 1}-\operatorname{Int} t_{P e 2}+\operatorname{Int} t_{P e 3}+\operatorname{Int} t_{P e 4}+\operatorname{Int} t_{P e 5}\right) \\
& \Delta t_{n e 2}=T_{d}-\Delta t_{\text {Nel }}, \Delta t_{n e 3}=\frac{-d}{2 f_{s}}-T_{d}, \Delta t_{n e 4}=T_{d}, \Delta t_{n e 5}=\frac{1}{2 f_{s}}-\frac{-d}{2 f_{s}}-T_{d}
\end{aligned}
$$

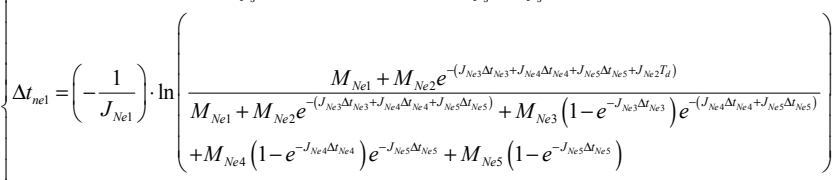

$$
\begin{aligned}
& J_{n e 1}=\frac{R_{a c}+2 R_{o n H}}{L_{a c}}, J_{n e 2}=\frac{R_{a c}+2 R_{o n H}}{L_{a c}}, J_{n e 3}=\frac{R_{a c}+2 R_{o n H}+4 N^{2} R_{o n L}}{L_{a c}}, J_{n e 4}=\frac{R_{a c}+4 N^{2} R_{o n L}}{L_{a c}} \\
& J_{n e 5}=\frac{R_{a c}+2 R_{o n H}+4 N^{2} R_{o n L}}{L_{a c}}, M_{n e 1}=\frac{V_{1}+2 N\left(V_{2}+2 V_{d L}\right)}{R_{a c}+2 R_{o H}}, M_{n e 2}=\frac{-2 N\left(V_{2}+2 V_{d L}\right)+V_{1}}{R_{a c}+2 R_{o u}} \\
& M_{n e 3}=\frac{V_{1}+2 N V_{2}}{R_{a c}+2 R_{o n H}+4 N^{2} R_{o n L}}, M_{n e 4}=\frac{2 N V_{2}-\left(V_{1}+2 V_{d H}\right)}{R_{a c}+4 N^{2} R_{o n L}}, M_{n e 5}=\frac{2 N V_{2}-V_{1}}{R_{a c}+2 R_{o n H}+4 N^{2} R_{o n L}}
\end{aligned}
$$

(17) $V_{2} \rightarrow V_{1}$, Mode $f$ : 


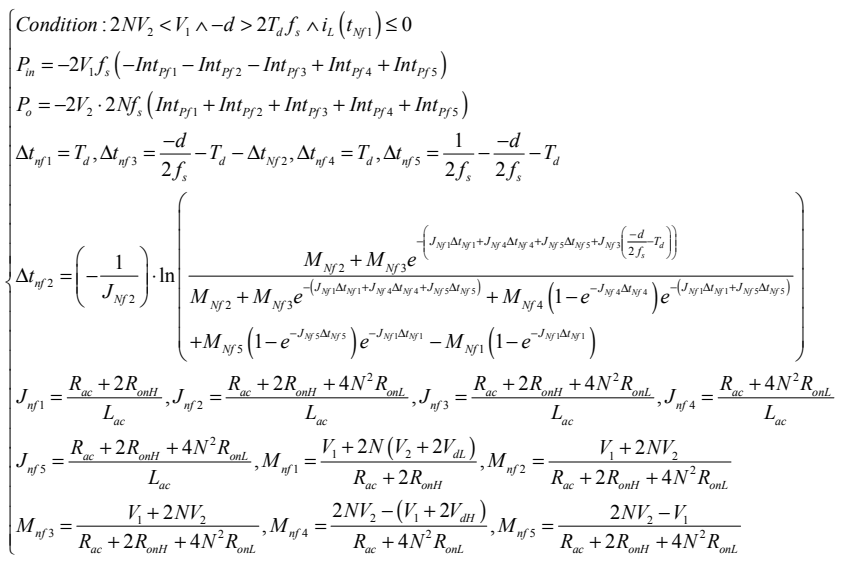

(19) $V_{2} \rightarrow V_{l}$, Mode $h$ :

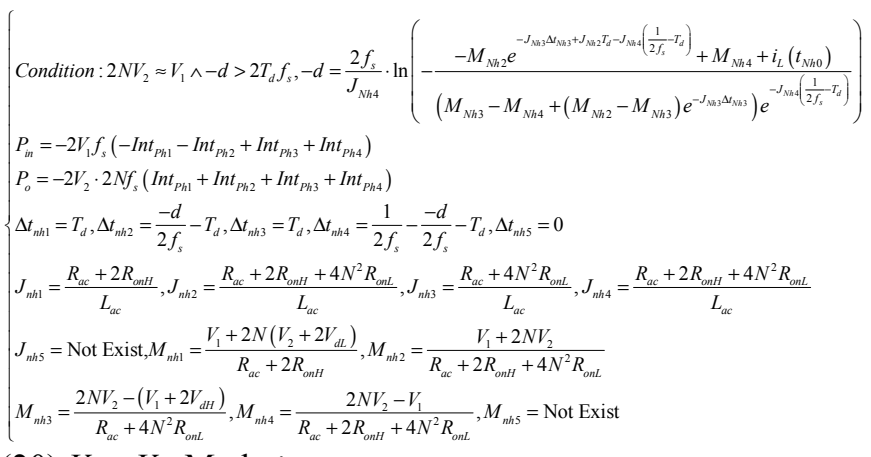

(20) $V_{2} \rightarrow V_{1}$, Mode $i$ :

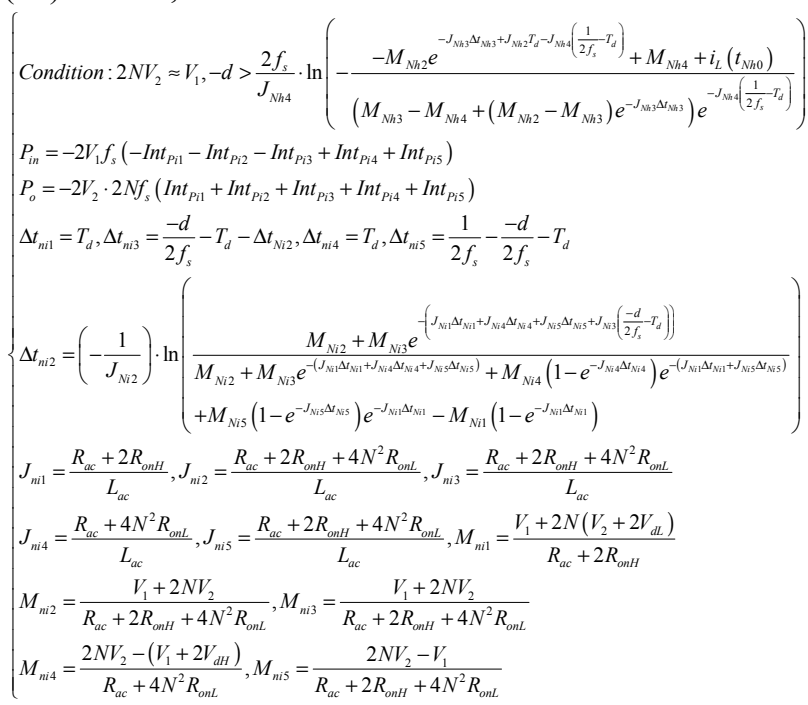

